\title{
Brunneroma: Unusual Case of Gastroduodenal Intussusception
}

\author{
"Dr. Hemendra Kumar ${ }^{1}$,Dr Anil Heroor ${ }^{2}$, Dr. Arul Vanan ${ }^{3}$ \\ ${ }^{1}$ (colorectal surgery, fortis hospital,Mumbai; india) \\ 2 (onco-surgery, fortis hospital,Mumbai; india) \\ 3 (general surgery, fortis hospital,Mumbai; india)) \\ *Corresponding author: Dr. Hemendra Kumar *
}

\begin{abstract}
Introduction: Brunner organ hamartoma, otherwise called brunneroma, is a rare benign tumor of the duodenum. These benign tumors can be asymptomatic or can present with obstructive manifestations as well as gastrointestinal bleeding. Intussusception is an uncommon introduction for a brunneroma. ). The distribution of Brunner's gland hamartomas is duodenal bulb (57\%), the second (27\%) and third (5\%) portions of the duodenum, the pyloric channel (5\%), jejunum (2\%), and proximal ileum (2\%).

Case Report: A 55 year old female came to the gastrointestinal surgery division with complain of epigastric pain intermittent, and aggravated by eating food and associated with nonbilious, non-projectile. There was no history of hematemesis, melena, jaundice, weight loss, or anorexia. Radiological investigations were suggestive of gastric outlet obstruction. The patient underwent a distal gastrectomy. A diagnosis of Brunner's gland adenoma was made on histopathological examination.

Conclusion: Our case was unique as an uncommon tumor Brunner's organ hamartoma, rare location: pyloric, around $8 \mathrm{~cm}$, and rare clinical presentation of Gastroduodenal intussusception. In spite of the fact that brunneroma is an uncommon element, it ought to continuously be considered as a differential conclusion of duodenal polypoidal disease. Larger disease can cause Gastroduodenal intussusceptions and can display with obstructive indications.
\end{abstract}

Keyword: Brunner gland hamartoma, Brunneroma, intussusception, obstruction.

\section{Introduction}

Brunner organ hamartoma, otherwise called brunneroma, is a rare benign tumor of the duodenum These benign tumors can be asymptomatic or can present with obstructive manifestations as well as gastrointestinal bleeding. Intussusception is an uncommon introduction for a brunneroma with fewer than 200 cases detailed in the literature. Endoscopic biopsies are regularly nondiagnostic, and endoscopic expulsion might be troublesome. These may copy tumors, for example, leiomyomas, gastrointestinal stromal tumors, carcinoid tumors, neurogenic tumors, or abnormal pancreas. For giant hamartomas, surgical extirpation is frequently essential furthermore, harmful degeneration is uncommon. We exhibit an instance of gastric outlet obstruction secondary to a giant Brunner gland hamartoma, which created rare gastroduodenal intussusceptions.

\section{Case Report}

A 55 year old female of Indian ethnicity came to the gastrointestinal surgery division with complain of epigastric agony from last 10-15 days. The pain was moderate in intensity, intermittent, and aggravated by eating food (both solids and liquids). It was related with episodes of nonbilious, non-projectile. There was no history of hematemesis, melena, jaundice, weight loss, or anorexia. There was no critical therapeutic or surgical history of past ailment. On examination, there was mild epigastric tenderness. On palpitation there was no palpable mass, guarding, or rigidity. Her vital signs were stable.

The blood parameters were inside typical range. An initial ultrasound was performed \& impression was delayed emptying stomach with mixed echogenic mass measuring about $4.9 \times 4.1 \times 3.5 \mathrm{~cm}$ noted in the region of duodenum.A multidetector triphasic CT scan of the abdomen and pelvis was performed .It revealed a large heterogeneous enhancing soft tissue mass approximately measuring approximately $9 \times 4.6 \mathrm{~cm}$, is seen in duodeno-jejunal region with intussusceptions of this loops with associated swirling of mesenteric vessels in the intussuscepted small bowel loop. However these intussusceptions are incomplete. There is smooth passage of oral contrast distally with no abnormal distension of stomach is seen proximally. Upper GI endoscopy report suggest of large peduculated polyp /GIST with gastric outlet obstruction (11/3/17) \& a large pyloric peduculated polyp causing jejunal intussusceptions.

On exploratory laparotomy, the pylorus was found to be invaginated into the duodenum. Gastroduodenal intussusceptions were noted. After longitudinal duodenotomy, a peduculated ring-shaped large polyp $(8 \mathrm{~cm})$ originating from the pyloric ring was seen and excised with its base and a Billroth II 
reconstruction was performed.The respected specimen was solid, irregular, ulcerative and grayish browncolored with few cystic spaces(Figure 1,2).
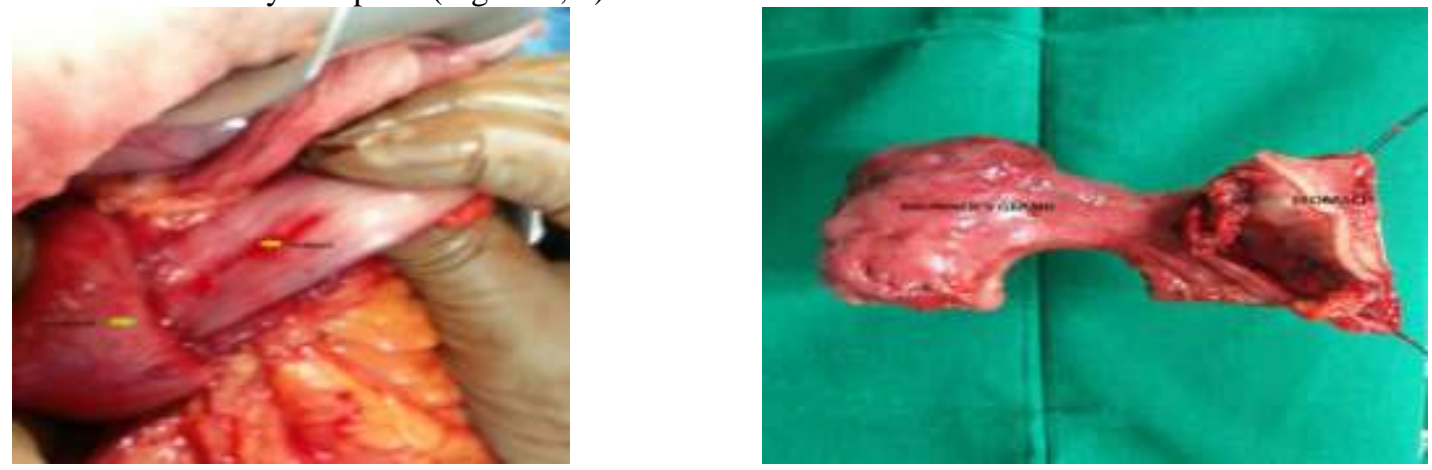

1. Gastroduodenal intussusceptions Fig 2. specimen

Microscopically, sections show gastroduodenal mucosa. Gastric mucosa shows mild chronic atropic gastritis with H. pylori. Underlying submucosa and muscle layer shows Brunner's gland adenoma/ hamartoma no evidence of malignancy. The post-operative course was uneventful, and the patient is eating well and thriving. One month later, the patient was asymptomatic; the upper gastrointestinal endoscopy showed patent pylorus and duodenum without any mass

\section{Discussion}

Brunner's glands are known as mucus-secreting glands found mainly in the duodenum, although they are occasionally found in the pylorus and distally as far as the jejunum (1). Polyps of these glands are rare benign lesions, accounting for less than $1 \%$ of small intestinal tumors (2). Brunner's gland polyps are mostly located in the proximal duodenum and are usually pedunculated, and a size greater than $2 \mathrm{~cm}$ is exceedingly rare $(3,4)$. Goldman $(5)$, a well-known reviewer of the Brunner's gland "hyperplastic" polyps, pointed out that the histological architecture of these lesions consists of a combination of ductal and acinar structures with fibromuscular and adipose elements. Furthermore, lack of an encapsulation fits the criteria for neither adenoma nor hyperplasia. Accordingly, he was the first to stress that these features strongly suggest a hamartomatous origin for Brunner's gland polyps (5). The distribution of Brunner's gland hamartomas is duodenal bulb (57\%), the second (27\%) and third (5\%) portions of the duodenum, the pyloric channel $(5 \%)$, jejunum (2\%), and proximal ileum $(2 \%)(6)$.

They are normally asymptomatic and are found by chance amid endoscopy. Symptomatic cases most normally present with gastrointestinal bleeding and obstruction (7). Bleeding is often chronic and may be manifested as chronic anemia. Obstructive indications ordinarily happen when they are bigger than $2 \mathrm{~cm}(8)$. Brunner's gland adenoma may present with gastric outlet obstruction (9), duodenal obstruction, as in our case, or occasionally with the intussusception of the duodenal wall $(10,11,12,13)$. A high index of suspicion is required while diagnosing brunneroma on imaging. The standard imaging modalities employed include barium meal, ultrasound, CT, EUS, and upper gastroendoscopy. The findings on barium and ultrasound are that of nonspecific benign lesions like stromal tumors, carcinoid, or aberrant pancreatic tissue. A CT scan is done to see the extent of the lesion and determine its relationship to adjacent structures. The American Institute of Radiologic Pathology uses the terms "Brunner gland hyperplasia" for lesions $<5 \mathrm{~mm}$ in size and "Brunner's gland hamartoma" for lesions $>5 \mathrm{~mm}$ in size. The present case had chronic intermittent duodenal obstruction at the gastroduodenal due to the intermittent prolapsed of the polyp. This was evidenced by the presence of a dilated duodenum and the symptoms of gastroesophageal reflux. This obstruction was related to the large size of the polyp and, probably, also to duodenal intussusception $(14,15)$.

Even though these tumors are dysembryoplastic lesions and exhibit a benign course without malignant predisposition $(16,17)$, the literature reports a proven case of cancer developing from this origin $(18,19)$. The differential diagnosis usually includes leiomyomas, adenoma of the mucosal glands, carcinoid tumor, lipoma, prolapsed pyloric mucosa, or antral polyp (20). We found this patient, who presented with recurrent episodes of vomiting and late postprandial abdominal pain, to have a polypoid Brunner's gland hamartoma with a long stalk in the pyloric ring.

Etiology stays indistinct however numerous theories have been proposed. Due to the "anti-acid" capacity of Brunner's organs, an expanded corrosive discharge could animate these structures to experience hyperplasia, however no relapse was found with acid secretion inhibitors $(21,22)$. It has additionally been recommended that $\mathrm{H}$. pylori disease may assume a part, since it was found in $71 \%$ of Brunner's organ hyperplasia (23) yet the extraordinary uncommonness of this element and the high predominance of H. pylori contamination doesn't permit clear conclusions. Nevertheless, many factors were proposed for its pathogenesis, such as local irritation, parasympathetic activity, chronic pancreatitis, and Helicobacter pylori infection. 


\section{Conclusion}

Our case was unique as an uncommon tumor Brunner's organ hamartoma, rare location: pyloric, around $8 \mathrm{~cm}$, and rare clinical presentation of Gastroduodenal intussusception. In spite of the fact that brunneroma is an uncommon element, it ought to continuously be considered as a differential conclusion of duodenal polypoidal disease. Larger disease can cause Gastroduodenal intussusceptions and can display with obstructive indications.

\section{References}

[1]. Angevine JM, Lowell DM. Brunner gland adenomas. Mil Med 1968; 133: 372-5.

[2]. Ladd WE. Congenital obstruction of the duodenum in children. N Engl J Med 1932; 206: 277-83.

[3]. Kouraklis G, Kostakis A, Delladetsima J. Hamartoma of Brunner's gland causing massive hematemesis. Scand J Gastroenterol 1994; 29: 841-3.

[4]. Levine JA, Burgart LJ, Batts KP, Wang KK. Brunner's gland hamartomas: clinical presentation and pathological features of 27 cases. Am J Gastroenterol 1995; 90: 290-4.

[5]. Goldman RL. Hamartomatous polyp of Brunner's gland. Gastroenterology 1963; 44: 57-62.

[6]. Walden DT, Marcon NE. Endoscopic injection and polypectomy for bleeding Brunner's gland hamartoma: case report and expanded literature review. Gastrointest Endosc 1998; 46: 403-7.

[7]. Levine JA, Burgart LJ, Batts KP, Wang KK. Brunner's gland hamartomas: clinical presentation and pathological features of 27 cases. Am J Gastroenterol 1995; 90:290-4. [PMID 7847303]

[8]. de Nes LC, Ouwehand F, Peters SH, Boom MJ. A large Brunner's gland hamartoma causing gastrointestinal bleeding and obstruction. Dig Surg 2007; 24:450-2. [PMID 18025785]

[9]. Lingawi SS, Filipenko JD. Brunner's gland hamartoma causing gastric outlet obstructive symptoms. South Med J 1998; 91:964-5. [PMID 9786295]

[10]. Lempke RE. Intussusception of the duodenum: report of a case due to Brunner's gland hyperplasia. Ann Surg 1959; 150:160-6. [PMID 13661844]

[11]. Kellogg EL. Intussusception of the duodenum caused by adenoma originating in Brunner's glands. Med J Record 1931; 134:440-2.

[12]. Chuang JH, Chen WJ. Duodenojejunal intussusception secondary to hamartomatous polyp of Brunner's glands. J Pediatr Gastroenterol Nutr 1991; 13:96-100. [PMID 1919957]

[13]. Peetz ME, Moseley HS. Brunner's gland hyperplasia. Am Surg 1989; 55:474-7. [PMID 2662841]

[14]. Jung Y, Chung IK, Lee TH, et al. Successful endoscopic resection of large pedunculated Brunner's gland hamartoma causing gastrointestinal bleeding arising from the pylorus. Case Rep Gastroenterol. 2013;7:304-7.

[15]. Block KP, Frick TJ, Warner TF. Gastrointestinal bleeding from a Brunner's gland hamartoma: characterization by endoscopy, computed tomography, and endoscopic ultrasound. Am J Gastroenterol. 2000;95:1581-3. PMid:10894601.

[16]. Attanoos R, Williams GT. Epithelial and neuroendocrine tumors of the duodenum. Semin Diagn Pathol 1991; 8: 149- 62.

[17]. DeSilva S, Chandrarsoma P. Giant duodenal hamartoma consisting mainly of Brunner's glands. Am J Surg 1977; 133: 240-3.

[18]. Christie AC. Duodenal carcinoma with neoplastic transformation of the underlying Brunner's glands. Br J Cancer 1953; 7: 65-7.

[19]. Matsui T, Iida M, Fujischima M, et al. Brunner's gland hamartoma associated with microcarcinoids. Endoscopy 1989; 21: 37-8.

[20]. Bastounis E, Pikoulis E, Leppaniemi A, et al. Polypoid hamartoma of Brunner's gland of the duodenum. Dig Surg 1999; 16: 431-3.

[21]. Pironi D, Vendettuoli M, La Gioia G, Arcieri S, Filippini A. A large Brunner's gland adenoma: an unusual cause of gastrointestinal bleeding. Case report and literature review. Ann Ital Chir 2010 Mar-Apr;81(2):147-151.

[22]. Levine JA, Burgart LJ, Batts KP, Wang KK. Brunner's gland hamartomas: clinical presentation and pathological features of 27 cases. Am J Gastroenterol 1995 Feb;90(2):290-294.

[23]. Levine JA, Burgart LJ, Batts KP, Wang KK. Brunner's gland hamartomas: clinical presentation and pathological features of 27 cases. Am J Gastroenterol 1995 Feb;90(2):290-294. 